\title{
Simulation of Low-cycle Fatigue in Integral Abutment Piles
}

\author{
Robert Hällmark \\ M.Sc. Civ. Eng. \\ Ramböll Sverige AB \\ Luleå, Sweden \\ Robert.Hallmark@ramboll.se
}

\author{
Peter Collin \\ Professor \\ LTU / Ramböll Sverige AB \\ Luleå, Sweden \\ Peter.Collin@ramboll.se
}

\author{
Hans Pétursson \\ Lic. Techn. \\ Ramböll Sverige AB \\ Falun, Sweden \\ Hans.Petursson@ramboll.se
}

\author{
Bernt Johansson \\ Professor \\ Luleå Univ. of Technology \\ Luleå, Sweden \\ Bernt.Johansson@ltu.se
}

\begin{abstract}
Summary
Integral abutment bridges are bridges without any expansion joints, and their largest benefits are the lower construction- and maintenance costs. In order to build longer integral bridges it might be necessary to allow plastic hinges to be developed in the piles. Lateral thermal movements are the major reason to plastic deformations, and since temperature variations are cyclic it has to be proved that low-cycle fatigue will not occur. A simulation of the pile strain spectra should be able to take into account the strains caused by temperature variations and traffic loads. Such a model has been created from real temperature data and traffic loads measured by Bridge-Weigh-In-Motion technology. Monte Carlo simulations have been performed in order to simulate daily and annual temperature changes as well as the varying traffic loads. Piles strains have been calculated, and their fatigue effect has been evaluated.
\end{abstract}

Keywords: Integral abutments, jointless bridges, low cycle fatigue, Monte Carlo simulation.

\section{Introduction}

Integral abutment bridges are bridges without any expansion joints, and their largest benefits are the lower construction- and maintenance costs. This paper deals with a type of integral abutment shown in Fig. 1 with concrete end walls supported by steel piles. The top of the piles will experience lateral displacements as well as rotations, as a result of thermal movements, temperature gradients, and traffic loads. In order to build longer integral bridges, it is necessary to allow the development of plastic strains in the piles. Lateral thermal displacements are the major reason to plastic strains, and since the temperature variations are cyclic it must be proved that low-cycle fatigue failure will not occur.

A calculation method called the Equivalent Cantilever Method (see 2.2) has been used in order to create a model of the abutment-pile-soil interaction. The pile strains were expressed as a function of varying parameters such as effective bridge temperature, traffic load, and temperature gradient. The effective bridge temperature was simulated by using a mathematical temperature model which had been adapted to real temperature measurements. Daily maximum and minimum temperatures are generated for every single day during the bridge service lifetime, giving daily- as well as annual strain cycles. Traffic loads are simulated by using a traffic load model based on the gross weight distribution of the lorries that crosses the bridge. Data from measurements of traffic intensity and lorry gross weights, at two Swedish roads, have been used to create the traffic simulation model.

\section{Low-cycle Fatigue Simulation Model}

Thermal expansion and contraction of bridge decks are normally handled by expansion joints. In an integral abutment bridge the abutments will be pushed towards the backfill or pulled away, as a result of the bridge longitudinal expansion. Variations in bridge temperature will appear both daily and seasonally and lead to a cyclic loading procedure of the piles. The piles will deflect under the 
loading and plastic deformations may occur now and then. Low-cycle fatigue may be a possible failure mode, which may reduce the bridge's lifetime [1]. The ability of the piles to take lateral movements will be a very important parameter, as well as the lateral stiffness of the soil that surrounds the upper part of the piles.

\subsection{Example Bridge - Leduån Bridge}

The bridge that has been used as a model in all of the simulations is a $40 \mathrm{~m}$ long one span integral abutment bridge. The bridge is a two lane roadway bridge, designed to be a crossing over the Leduån River close to the Swedish town Nordmaling, see Fig. 1. The piles used in the construction are steel pipe piles, $\varnothing 170 \times 10$, which are driven in straight lines perpendicular to the longitudinal bridge axis. Six end bearing piles are supporting each abutment. In order to study how the bridge behaves under traffic loads, temperature displacements etc. it is monitored continuously by Luleå University of Technology, since the end of 2006.

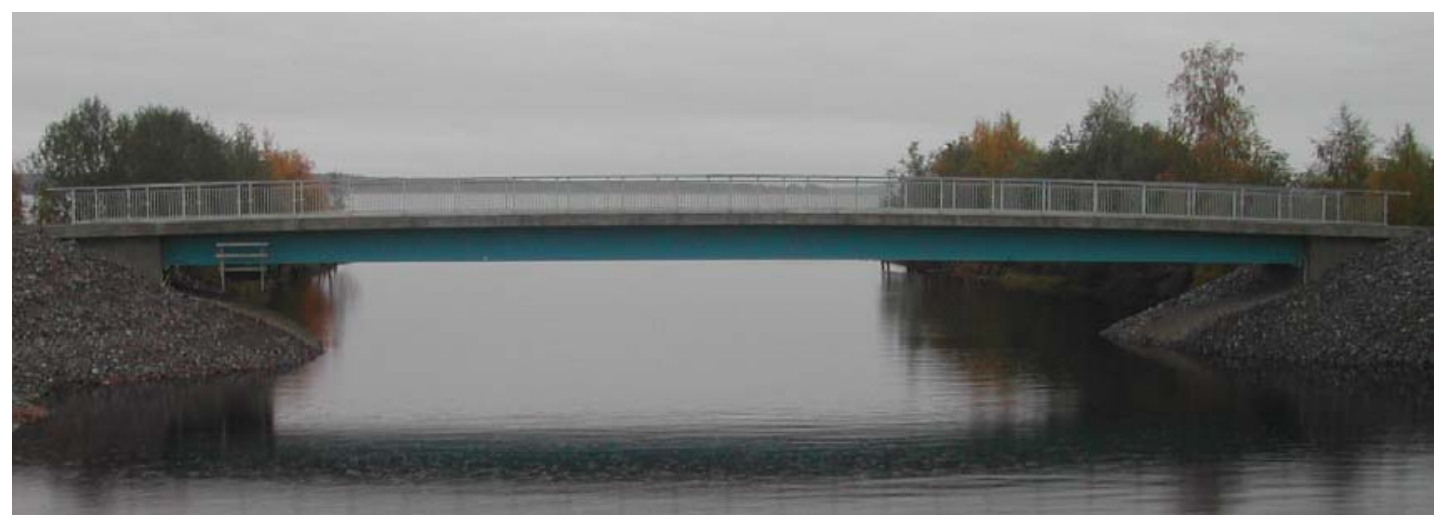

Fig. 1 View of the Leduån River Bridge.

\subsection{Calculation Model}

The interaction between piles and soil has been modelled by the Equivalent Cantilever Method described in [2] [3]. In this model, piles are replaced by equivalent cantilevers. The length of the pile in the equivalent cantilever model, $\mathrm{L}_{\mathrm{equ}}$, is a function of pile- and soil properties. How $\mathrm{L}_{\text {equ }}$ is calculated is described in [2] [3]. Two different $\mathrm{L}_{\text {equ }}$ are used in the pile strain calculations, one for horizontal stiffness and one for bending moment. The first one is based on the assumption that the lateral pile stiffness of the equivalent cantilever pile equals the lateral stiffness of a pile embedded in soil. The other assumption says that the maximum moment in the equivalent cantilever equals the maximum moment in a pile embedded in soil. The pile strains were calculated according to the following expression,

$$
\varepsilon_{P}=\frac{\left(N_{\text {pile }}^{\text {dead }}+N_{\text {pile }}^{\text {trafic }}\right)}{A_{\text {pile }} \cdot E}+\left(\frac{3 \cdot \varnothing}{L_{\text {equ }, h}^{2}}\right) \cdot\left(\Delta_{\text {abut }}+H\left(\theta_{\Delta T}+\theta_{\text {traffic }}+\theta_{\text {dead }}\right)\right)+\left(\frac{2 \cdot \varnothing}{L_{\text {equ }, m}}\right) \cdot\left(\theta_{\Delta T}+\theta_{\text {traffic }}+\theta_{\text {dead }}\right) .
$$

$\mathrm{N}_{\text {pile }}$ normal force in a single pile

$\mathrm{A}_{\text {pile }}$ pile area

E the modulus of elasticity

$\varnothing \quad$ pile diameter

$\Delta_{\text {abut }}$ lateral abutment displacement $\theta \quad$ abutment rotations

$\mathrm{L}_{\text {equ, } h}$ equivalent cantilever length, horizontal stiffness

$\mathrm{L}_{\text {equ, } m}$ equivalent cantilever length, moment

$\mathrm{H}$ distance between the superstructures gravity centre and the level where the piles enter the abutment

\subsection{Temperature Simulations}

\subsubsection{Shade Air Temperature}

Shade air temperature measurements from different places indicate that seasonal temperature changes are varying almost like a sinus wave [1] [4]. Temperature measurements, in Stockholm, during a period of 5 years are used to illustrate the cyclic behaviour, see Fig. 2 . The input data has been compiled in [5]. 
The temperature has been studied at five locations in Sweden, and a mathematical model has been developed in order to perform a Monte Carlo simulation of the annual temperature changes as well

Daily mean temperature in Stockholm 2000-01-01 - 2004-12-31

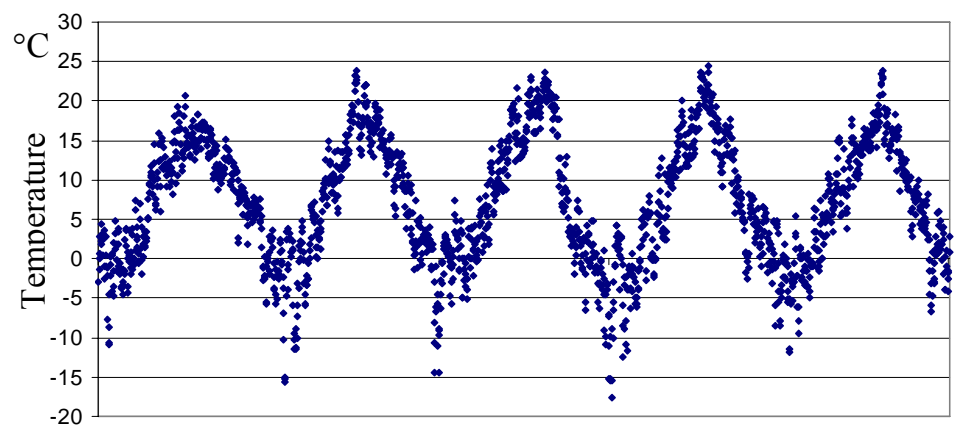

Fig. 2 Seasonal temperature changes in Stockholm during a period of five years. as the daily changes. The annual temperature variation is modelled by two separate sine curves: one which describes the daily maximum temperature and one which describes the daily minimum temperature. In order to deal with the randomness that is associated with temperatures, normal distributions are used. These are adapted to the mean daily maximum and minimum temperatures for each month, and to the extreme temperatures that occur once in fifty years at the studied locations. The following expression is suggested to be used, (2).

$$
T_{d, \max / \min }=T_{\max / \min a m p} \cdot \sin \left(\frac{t_{d}}{365} \cdot 2 \pi-t_{0}\right)+T_{\max / \min m}+N\left(\mu, \sigma_{\max / \min }\right) .
$$

\footnotetext{
$\mathrm{T}_{\mathrm{d} \max / \min } \quad$ simulated daily maximum respectively minimum temperatures

$\mathrm{T}_{\max / \min \text { amp }} \quad$ annual amplitude of the daily maximum respectively minimum temperatures

$t_{d} \quad$ time measured in days

$\mathrm{t}_{0} \quad$ factor introduced to shift the sinus curve horizontally to adjust it to measured temperature data

$\mathrm{T}_{\max / \min \mathrm{m}} \quad$ annual mean value of daily maximum and minimum temperatures

$\mathrm{N}\left(\mu, \sigma_{\max / \min }\right)$ normal distributions adapted to extreme temperatures and mean daily max/min temperatures
}

The mean values of the simulated daily temperature variations have been compared to measured temperatures, and it has been observed that the mathematical model is rather conservative concerning daily temperature variations. The daily temperature changes are overestimated by $10-$ $17 \%$, at the five studied locations.

\subsubsection{Temperature Differences between Deck and Girders.}

One negative and one positive temperature difference has been simulated every day during the bridge service lifetime. A conservative assumption has been used, saying that the positive and negative temperature differences will coincide with the daily minimum and maximum bridge temperature. Two log-normal distributions are used to model the temperature differences. The probability distributions are adapted to the extreme temperature differences that occur once in a year and once in fifty years according to ENV 1991-2-5. Fig. 3 illustrates a result from a simulation of negative and positive temperature differences during a period of 50 years.

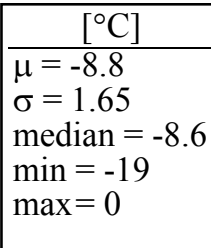

Fig. 3 Log-normal distributions, illustrated by the result from a Monte Carlo simulation.

\subsubsection{Effective Bridge Temperature}

Longitudinal thermal movements of a bridge are mainly governed by the effective bridge temperature (EBT). The simulated shade air temperatures are therefore transformed into EBTs, in this case by using the EBT model given in EN1991-1-5. The only input needed to this model is the shade air temperature and type of superstructure. The Leduån Bridge that has been used in this 
study is classified as a Group 2 bridge according to EN1991-1-5, and the EBT can be calculated according to the following expression,

$T_{E B T \max / \min }=4+T_{\text {shade } \max / \min } \quad\left[{ }^{\circ} \mathrm{C}\right]$.

\subsubsection{Temperature Movements}

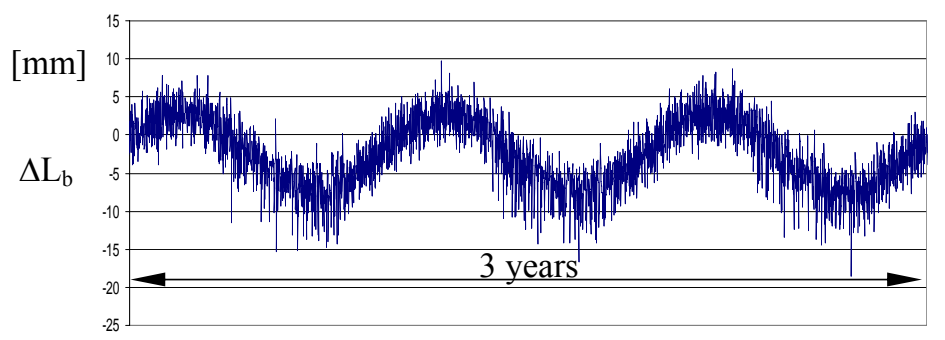

Fig. 4 Variation of bridge length for a composite bridge with a single span of $40.0 \mathrm{~m}$, located in Kiruna.
The abutment displacements, as a result of the expansion and contraction of the superstructure, can be described as

$\Delta_{\text {abut }}=\frac{\alpha \cdot \Delta T_{E B T} \cdot L_{b}}{2}$,

where $\alpha$ is the thermal coefficient of the superstructure and $\mathrm{L}_{\mathrm{b}}$ the length of the bridge. In Fig. 4, thermal movements are plotted over a period of time in order to illustrate the results from the temperature simulations.

\subsection{Traffic Load Simulation}

A traffic load model has been developed in order to study the real loads which the piles in an integral bridge will be subjected to. The load model is based on lorry loads from Bridge Weigh In Motion (BWIM) measurements and Annual Average Daily Traffic (AADT) values, measured with the Metor 2000 system. Second hand information has been used, and most of the information has been collected from [6]. Measurements from two Swedish roads have been studied. The roads and locations that have been studied is E22 close to the Swedish town Strängnäs and National Road 67 close to Tillberga. The traffic fatigue load model given in [7] has also been used in the calculations, in order to study the differences.

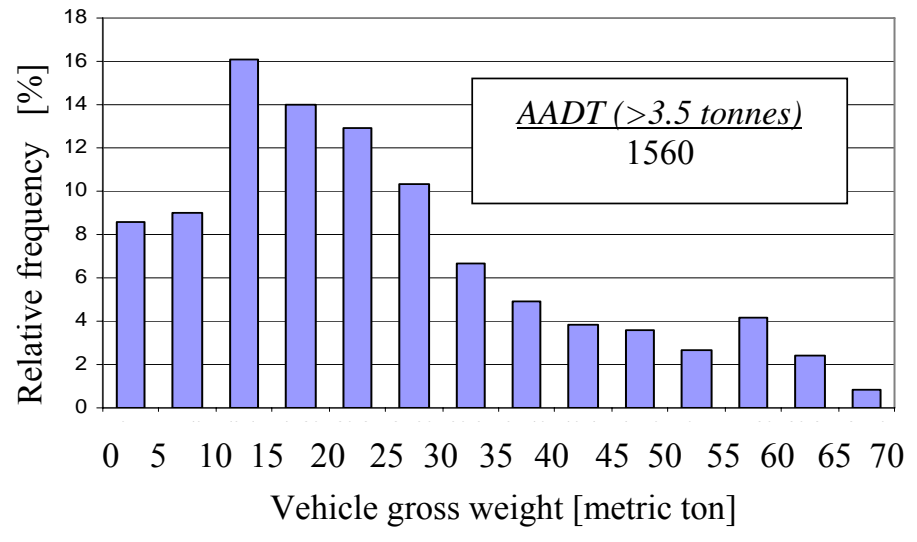

Fig. 5 Vehicle gross weight distribution at road E22Strängnäs.
If the load is doubled then the fatigue effect increases eight times. The weight of a passenger car is only a few percentage of the weight of a heavily loaded lorry. The passenger cars contribution to the fatigue will therefore be insignificant. Only vehicles with a weight above 3.5 tonnes are taken into consideration in the traffic fatigue load model. The AADT for vehicles with a weight $>3.5$ tonnes are used together with the gross weight distribution among these vehicles. An example of a gross weight distribution that has been used is shown in Fig. 5.

\subsubsection{Vehicle Models}

The vehicles with a gross weight $>3.5$ tonnes are divided into four groups, depending on their gross weight. One vehicle model is used to represent all vehicles in one group. When the vehicle models were created, the allowable vehicle loads according to the Swedish Traffic Regulation were taken into consideration, as well as results from a similar study [8]. Gross weight overloads of 6-25\% were allowed, since [6] states that $13.8 \%$ of the lorries (weighed by the BWIM-technique in Sweden during 2005) were overloaded. [6] states also that every third vehicle above 35 tonnes, was overloaded at least on one axel. A distributed lane load from traffic queues was also taken into consideration. The traffic load model works according to the following schedule, see Fig. 6. 
- Vehicle weight, $\mathrm{W}$, is generated from a gross weight distribution

- $\mathrm{W} \Rightarrow$ Vehicle type $1,2,3$ or 4

- Queue weight, q, is generated

- Normal force is calculated in the most exposed pile

- Rotation due to the traffic load is calculated

\begin{tabular}{lc|}
\hline & Weight interval [ton] \\
\hline Type 1: & $3.5<\mathrm{W}<28$ \\
Type 2: & $28 \leq \mathrm{W}<38$ \\
Type 3: & $38 \leq \mathrm{W}<55$ \\
Type 4: & $55 \leq \mathrm{W}<75$ \\
\hline
\end{tabular}

- Pile strain caused by the traffic load is calculated

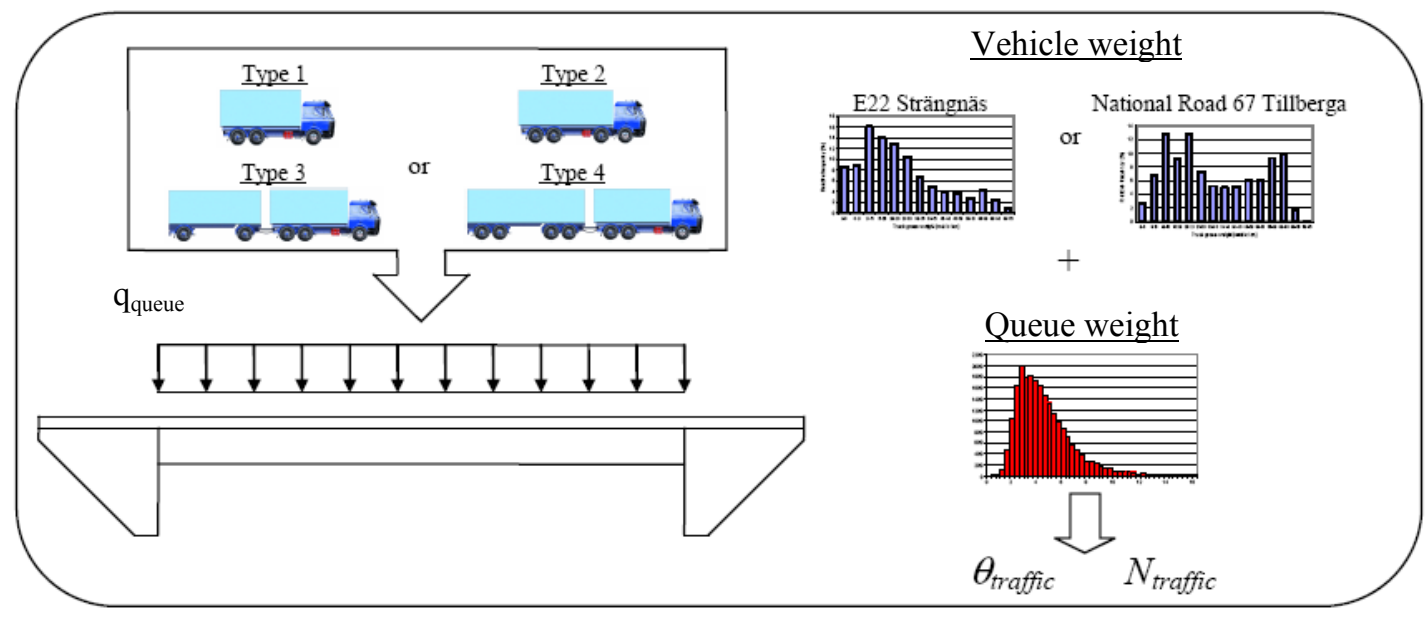

Fig. 6 Schematic illustration of traffic load model.

The six steps in the generation of pile strain cycles, due to traffic loads, are repeated every time a lorry crosses the bridge. In the example with road E22, there will be 1560 daily cycles, which gives 68 million cycles during the bridge service lifetime of 120 years. A Monte Carlo simulation is used to simulate 100000 traffic loads cycles for each road. These load cycles are taken as representative for the whole lifetime and repeated until the required number of cycles is achieved.

\section{Fatigue Calculations}

\subsection{Fatigue Model}

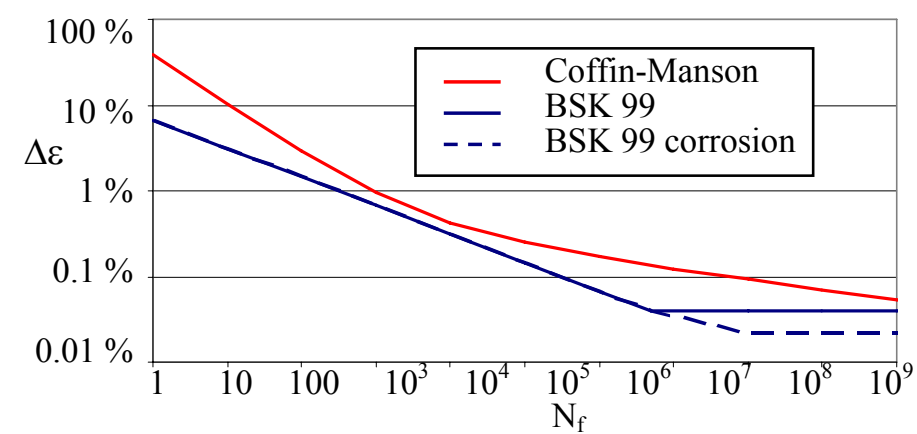

Fig. 7 Extrapolated $\varepsilon_{f}-N_{f}$ curve from [8] compared to Coffin-Manson's equation.
The fatigue calculations are strain based, since plastic deformations are allowed to occur. Two different models to evaluate the low-cycle fatigue have been studied, Coffin-Mansons's equation and the extrapolated $\varepsilon_{\mathrm{f}}-\mathrm{N}_{\mathrm{f}}$ curves from [9]. The latter was chosen since it is more conservative and simpler to use in the calculations. Fig. 7 illustrates the relationship between the suggested models, in a specific case where the detail fatigue category factor, $\mathrm{C}$, equals $112 \mathrm{MPa}$.

The cumulative fatigue is calculated according to the Palmgren-Miner's model,

$\sum_{i=1}^{n} \frac{n_{i}}{N_{f i}} \leq 1$

$n_{i} \quad$ the number of times a certain strain cycle is repeated

$N_{f i} \quad$ the number of cycles until failure for a strain cycle with a certain amplitude. 


\subsection{Definition of Strain Cycles}

The total strain in the piles is a function of variables with frequencies that spans from seconds up to a year. To be able to analyse the fatigue with the available computer programs, the total pile strain must be separated into different cycles. Two groups of cycles are identified, see Fig. 8.

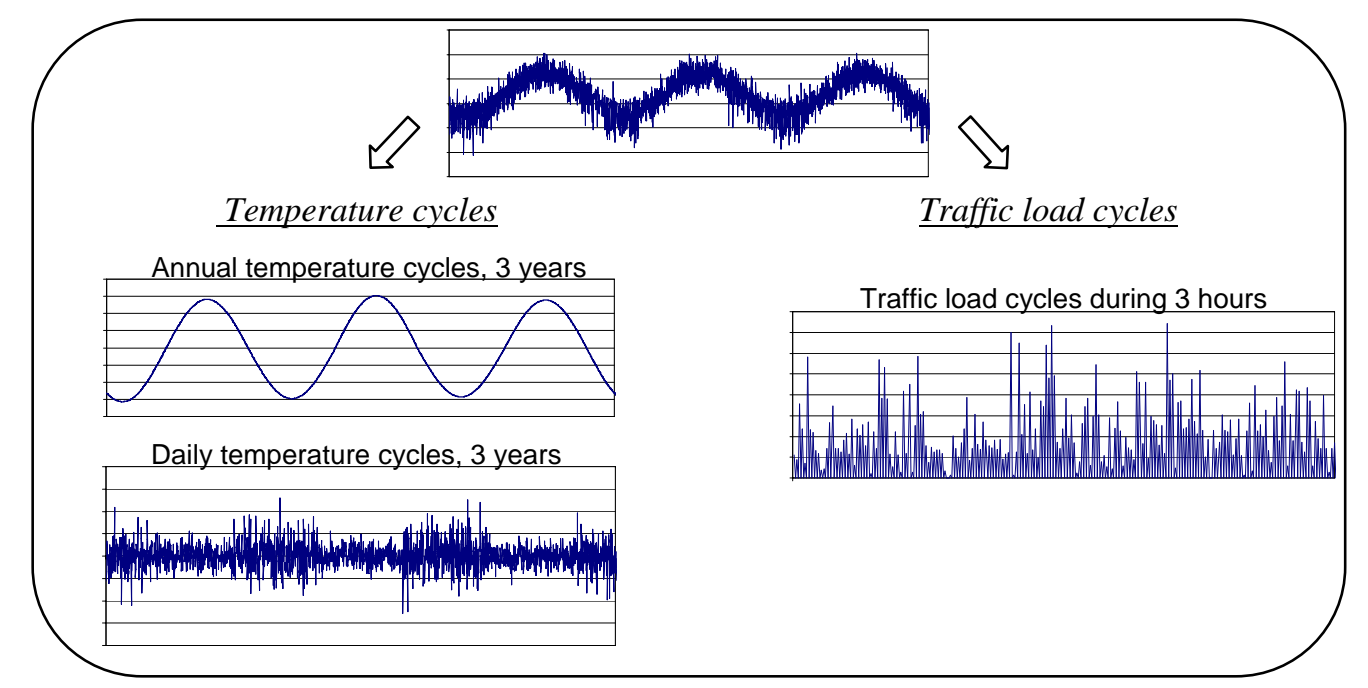

Fig. 8 Illustration of how the total pile strains can be separated into different type of cycles.

\subsection{Identification and Calculation of Cycles}

The amplitudes of daily strain cycles are varying a lot in contrast to the annual cycles, which are almost the same from one year to another. The temperature cycles are analysed together, which means that the daily variations have been superposed on the annual cycles. The simple ranges between peaks and valleys are known from the simulations, but it is harder to identify the cycles among these variations. A number of different techniques can bee used to identify cycles for irregular loading. [10] states that an agreement appears to have been reached that the preferable method is the rain-flow method. The rain-flow counting technique has therefore been used to identify the temperature cycles in this study.

Strain cycles caused by traffic loads are counted separately, since the period of such a cycle is very short compared to the temperature cycles. There is no need of any cycle counting technique either, since every single traffic load is modelled as one complete cycle with loading and unloading. If the traffic cycles should be superposed on the temperature cycles it would be necessary to use a time scale in seconds. This would give enormous amounts of data since the temperature and the traffic load has to be defined every time a vehicle crosses the bridge. A simplification with a separate analysis of temperature cycles and traffic load cycles will not affect the result too much, since all cycles still will be taken into consideration. If one unique vehicle load should be generated for every vehicle, it would give 68 million traffic cycles which has to be recorded. The traffic load distributions are not that complex, and a simulation of 100000 cycles are taken as representative for all of the traffic cycles.

The traffic loads will however give a contribution to the daily maximum strains. In order not to underestimate the maximum amplitudes of the daily cycles, a traffic strain is added to the daily maximum temperature strain. The minimum values will not be affected since the traffic always gives positive rotations and translations. Fig. 9 illustrates how the temperature strain cycles are combined with the traffic strain cycles. In the upper left corner, the varying strain due to daily temperature changes are illustrated during seven days. In the upper right corner, the varying traffic strain cycles during 12 hour is illustrated. The traffic strains during 12 hours are superposed on a part of the temperature strain curve, in order to illustrate the contribution from the traffic loads. The daily maximum strain will be higher and the minimum strain will not be affected. 


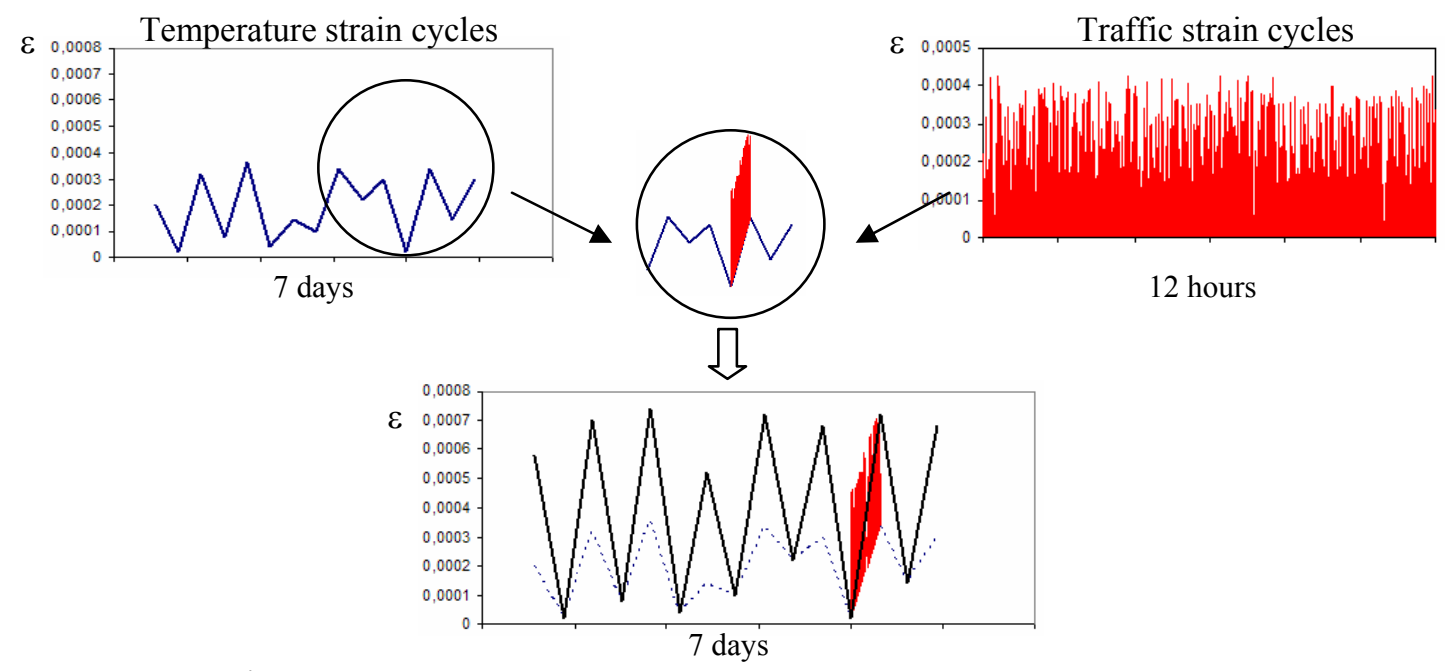

Fig. 9 Illustration of how daily strain ranges are modelled.

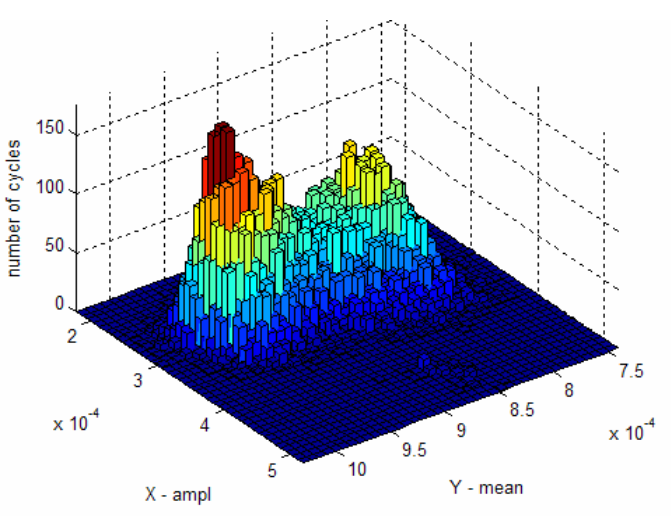

Fig. 10 3D-model of the distribution of both amplitudes and mean values for temperature induced strain cycles during 60 years.
A Matlab-script [11] has been used to identify the strain cycles, count them and sort them into bins. The number of cycles until failure will not be calculated for each individual cycle, since there are about 44000 temperature cycles during the bridge service lifetime. The temperature strain cycles are instead sorted according to their amplitude, and divided in 40 intervals. When the cumulative fatigue is calculated, all cycles within an interval are assumed to have the highest amplitude in that interval. Fig. 10 illustrates a result from rainflow counting of simulated temperature strain cycles during 60 years.

\subsection{Fatigue Simulations Results}

The cumulative fatigue has been simulated during 120 year for the pile which will suffer the highest strain variations. The following parameters have been varied:

- Corrosion

- Bridge length

- Soil model

- Bridge location

- $\quad$ Pile cross-section

\author{
No corrosion $\rightarrow 2.4 \mathrm{~mm}$ corrosion depth \\ $40 \rightarrow 200 \mathrm{~m}$ \\ Two different soil models \\ Five different locations in Sweden. \\ RR170x10 and HEM120
}

The soil models are based on the specific soil condition at Leduån Bridge, in which the upper part of the piles was surrounded by pipes $(\varnothing 600 \mathrm{~mm})$. The piles were wrapped in styrofoam sheets and loose sand was filled between the styrofoam sheets and the sheltering pipes. The undisturbed soil consists of fine sandy silt and silty fine sand, down to a depth of $6 \mathrm{~m}$. The soil below this depth will not affect the pile strains at the top. In this case there was silt/clay down to a depth of about $20 \mathrm{~m}$. [2] and [3] suggests that a properly filled pre-drilled hole shall be treated as soil without any lateral stiffness. This assumption has been used in one of the soil models, the original soil model. The alternative soil model is more conservative, since the filling in the pre-drilled hole is given the same properties as loose sand in-situ. The soil stiffnesses are calculated according to [7].

Some examples of results from the simulation processes are shown in Table 1. The bridge length has been varied in this case, while the other parameters have been kept constant. 
Table 1 Example of results from cumulative fatigue simulations, with the original soil model.

\begin{tabular}{|c|c|c|c|c|c|c|c|}
\hline \multirow{3}{*}{$\begin{array}{l}\mathrm{L}_{\text {equ. } \mathrm{m}} \\
\mathrm{L}_{\text {equ. }} \\
\text { Corrosion: } \\
\text { Location: }\end{array}$} & \multirow{2}{*}{$\begin{array}{l}3.143 \mathrm{~m} \\
2.773 \mathrm{~m} \\
2.4 \mathrm{~mm}\end{array}$} & \multicolumn{6}{|c|}{ Cumulative fatigue - Extrapolated $\varepsilon-N_{f}$ curves } \\
\hline & & Bridge length & $60 \mathrm{~m}$ & $80 \mathrm{~m}$ & $100 \mathrm{~m}$ & $150 \mathrm{~m}$ & $200 \mathrm{~m}$ \\
\hline & Karesuando & & 0.3851 & 0.5668 & 0.8292 & 1.884 & 3.694 \\
\hline
\end{tabular}

\section{Discussion and Conclusion}

The aim of this study was to investigate if, how and when low-cycle failure may occur in piles supporting integral abutment bridges. The conclusion is that low-cycle fatigue does not seem to be a problem at all in piles in integral bridges. At least as long as the length of the bridge does not exceed $100 \mathrm{~m}$, according to the calculation models that have been used. The effect of the location in Sweden does not seem to be very important. The maximum bridge length will however be a bit shorter in the north mountain regions. H-piles oriented for weak axis bending seems to be more suitable for integral abutment bridges than pipe piles with the same cross-sectional area. The large influence of the lateral soil stiffness can also be noted, higher soil stiffness decreases the fatigue lifetime considerably. In order to build longer integral bridges, lateral soil stiffness will be a key factor to deal with. The soil stiffness can for instance be lowered by using pre-drilled holes backfilled with loose sand or other soft materials, or by designing the back wall in a way which makes it possible for the piles to pass through the open air before they enter the abutments.

\section{References}

[1] DICLELI, M. and ALBHAISI, S. (2004). Effect of cyclic thermal loading on the performance of steel H-piles in integral bridges with stub abutments, Journal of Constructional Steel Research, 60, 161-182

[2] ABENDROTH, R.E. and GREIMANN, L.F. (1989). Rational Design Approach for Integral Abutment Brige Piles, Transportations Research Record 1223, 12-23

[3] ABENDROTH, R.E. and GREIMANN, L.F. (2005). Field Testing of Integral Abutments, Iowa DOT Project HR-399, Iowa State University and Iowa Department of Transportation, Iowa.

[4] ARSOY, S. (2000). Experimental and Analytical Investigations of Piles and Abutments of Integral Bridges, Doctoral Thesis, Virginia Polytechnic Institute and State University, Blacksburg, Virginia

[5] MOBERG, A. (2005). Daily temperature data for Stockholm old observatory 1756-2004, Available at: http://www.smhi.se/sgn0102/n0205/jordens_klimat/stockholm_daily.zip

[6] VÄGVERKET. (2006). BWIM-mätningar 2005 sammanfattning (BWIM-measurements 2005 Summary), Vägverket Publikation 2006:14, Borlänge, Sweden, ISSN: 1401-9612

[7] VÄGVERKET (2004). BRO2004 (the Swedish Bridge Code), Vägverket Publikation 2004:56, Borlänge, Sweden, ISSN: 1401-9612

[8] GETACHEW, A. (2003). Traffic Load Effects on Bridges, Doctoral Thesis, Royal Institute of Technology, Stockholm

[9] BOVERKET. (2003). Swedish Manual for Steel Structures - BSK99, Boverket, Karlskrona, ISBN: 91-7147-816-7

[10] ASM INTERNATIONAL. (1996). ASM Handbook Vol 19, Fatigue and Fracture, ASM International, Ohio, ISBN: 0-87170-385-8

[11] NIESŁONY, A. (2003). Rain flow for Matlab, Available at: http:/www.mathworks.com/ matlabcentral/fileexchange/loadFile.do?objectId=3026\&objectType=FILE\# (2006-07-16) 